\title{
POLYIMIDE COATING RECOVERING AN UNITY DUE TO SELF-HEALING OF MICRODAMAGES AND MICRODEFECTS
}

\author{
Ye.Auezkhanov, B.Khudaibergenov, T. Akhmetov, R. Iskakov
}

Polymeric composites on the basis of microencapsulated in the silico-organics - TMPTA, incorporated in polyimide coverings are received. The received composites possess function of a self-healing of places of microdamages at the expense of polymerization under the influence of an ultraviolet following of destroyed microcapsules TMPTA. The received materials can be used in the aviation and space industry for prolongation of service of protective polymeric coverings and films.

\section{МИКРОДЕФЕКТТЕР МЕН МИКРОЖАРЫКТАРДЫ ҚАЛПЫНА КЕЛТІРЕТІН КОМПОЗИЦИЯЛЫК ПОЛИИМИДТІК ЖАПКЫШТАР}

\author{
Е. Ауезханов, Б. Худайбергенов, Т. Ахметов, Р. Искаков
}

ТМПТА-ның силико-органикалық микрокапсуласында инкапсулденген полиимидтік жапқышпен инкорпорленген полимерлік композиттер алынды. Алынған композиттерін ТМПТА микрокапсуларынан шығатын ультракүлгіннің әсерінен полимерлену есебінен микробұзылған орындарды өздігінен жөндеу қасиеттері болады. Алынған материалдарды авиациялық және ғарыштық өндірістерде қорғаныс жабылымдар мен қабыршықтар қызмет ету мерзімін ұзарту үшін пайдалануға болады.

УДК 541.124

\section{РАЗРАБОТКА СПОСОБА ИЗВЛЕЧЕНИЯ БЕРИЛЛИЯ ИЗ ГРУППЫ МИНЕРАЛОВ ГЕНТГЕЛЬВИНА В УСЛОВИЯХ ПЕРЕРАБОТКИ МИНЕРАЛЬНОГО СЫРЬЯ}

\author{
Х.К.Оспанов, Г.М.Мутанов, Б.Ж.Арынов, С.К.Кожахметов, Б.А.Рыбакова, \\ Н.Х.Оспанова, А.Б.Байболдиева. \\ Казахский национальный университет им. аль-Фараби, г.Алматыf \\ ТОО "Ульба",г.Усть-Каменогорск \\ Ospanov_10_10@mail.ru
}

На основе термодинамических, кинетических исследований и методом математического планирования эксперимента выбрано оптимальное условие извлечения бериллия из мономинеральньх образцов группь гентгельвинов с использованием растворов соляной кислоть при нагревании реакционной системы при температуре $80^{\circ} \mathrm{C}$. Впервые предложен новый способ извлечения бериллия из группы минералов гентгельвина.

Существующие способы вскрытия бериллийсодержащего сырья имеют серьезные недостатки из-за того, что извлечения бериллия из них осуществляется только при высоких температурах, что не выгодно как в экономическом, так и в экологическом отношении (выделение вредных токсических газов, высокие энергозатраты, необходимость огнеупорных материалов) [1-9].

В связи с этим в настоящее время актуальной задачей является разработка новых технологий переработки бериллийсодержащего сырья, в том числе гидрохимических способов, соответственно и поиск новых эффективно действующих реагентов для вскрытия бериллийсодержащего сырья.

Наиболее перспективными являются гидрохимические методы, заменяющие высокотемпературные способы извлечения бериллия из бериллийсодержающего сырья, представленного, в основном, в виде минералов: хризоберилла, фенакита, бертрандита, даналита, гельвина, гентгельвина, эвклаза.

Однако до сих пор отсутствуют даже элементарные попытки поиска целесообразных путей растворения бериллиевых минералов с применением растворителей в условиях 
гидрохимического процесса, не говоря о теоретических основах процессов переработки бериллийсодержащего сырья. Это связано с тем, что большинство минералов бериллия трудно растворимые, т.е. термодинамически устойчивые соединения.

Подбор эффективно действующих растворителей весьма затруднителен. До сих пор отсутствуют научные основы разработки гидрохимических методов, методов переработки бериллийсодержащего сырья, а также научно обоснованные подходы к выбору эффективно действующих реагентов - растворителей.

Поэтому основной задачей данного исследования является разработка нового способа вскрытия бериллийсодержащего сырья с использованием эффективно действующих растворителей на основе научно-обоснованного подхода с привлечением нетрадиционного термодинамического и кинетического методов при относительно низкой температуре.

При гидрохимическом методе различия в реакционной способности минералов и неорганических материалов по отношению к конкретному реагенту-растворителю можно проанализировать, в основном, с учетом физико-химических свойств, как самих минералов, так и реагентов-растворителей. В связи с этим, в разработке новой технологии бериллия использованы материалы двух научных открытий[10]. Международная ассоциация авторов научных открытий выдала Х.К.Оспанову диплом № 283 на открытие «Закономерность скорость растворения труднорастворимых минералов в комплексообразующих растворах и окислительных средах» и наградила автора серебряной медалью (Москва, 2003 г.), а также диплом № 373 на открытие «Закономерность изменений эффективности действия растворяющих реагентов и последовательность прохождения конкурирующих реакций, протекающих на границе раздела твердое тело-жидкость», (золотая медаль, Москва, 2009 г.).

Поскольку минералы бериллия сильно различаются и по атомному составу, мы также пользовались величинами средней атомной энергии Гиббса образования $-\Delta_{f} \bar{G}^{0}$, отнесенными к сумме числа соответствующих атомов. (Таблица 2), как в работах [10-20].

Аналогичные сведения о различии реакционной способности для минералов бериллия основываются на величинах средней атомной энергии Гиббса образования. Сравнительный анализ $-\Delta_{f} \bar{G}^{0}$ минералов бериллия показывает, что с энергетической точки зрения последовательность их растворения должна изменяться в ряду от даналита к бериллу; при этом наибольшую реакционную способность, при прочих равных условиях, должен проявить даналит, затем гентгельвин, гельвин. Они составляют группу гентгельвинов. Далее по реакционной способности следуют бертрандит, эвклаз, бавенит, барилит, фенакит, берилл.

Таблица 1 - Стандартные значения энергии Гиббса образования и средняя атомная энергия Гиббса образования минералов бериллия. $-\Delta f \bar{G}^{0}$

\begin{tabular}{|l|l|l|l|c|}
\hline & Минерал & Формула & $\begin{array}{l}-\Delta f \mathrm{G}^{0} \\
\text { кДж/моль }\end{array}$ & $\begin{array}{c}-\Delta_{f} \bar{G}_{298} \\
\text { кДж/моль } \\
\text { атом }\end{array}$ \\
\hline & Даналит & $\mathrm{Fe}_{8}\left(\mathrm{BeSiO}_{4}\right)_{6} \mathrm{~S}_{2}$ & 10779 & 237 \\
\hline & Гентгельвин & $\mathrm{Zn}_{8}\left(\mathrm{BeSiO}_{4}\right)_{6} \mathrm{~S}_{2}$ & 11422 & 248 \\
\hline & Гельвин & $\mathrm{Mn}_{8}\left(\mathrm{BeSiO}_{4}\right)_{6} \mathrm{~S}_{2}$ & 11771 & 256 \\
\hline & Бертрандит & $\mathrm{Be}_{4}\left(\mathrm{Si}_{2} \mathrm{O}_{7}\right)(\mathrm{OH})_{2}$ & 4403 & 259 \\
\hline & Эвклаз & $\mathrm{Al}_{2}\left(\mathrm{Be}_{2} \mathrm{Si}_{2} \mathrm{O}_{8}\right)(\mathrm{OH})_{2}$ & 4710 & 262 \\
\hline & Бавенит & $\mathrm{Ca}_{4}\left(\mathrm{Be}_{2} \mathrm{Al}_{2} \mathrm{Si}_{9} \mathrm{O}_{26}\right)(\mathrm{OH})_{2}$ & 12843 & 279 \\
\hline & Барилит & $\mathrm{Ba}_{\left(\mathrm{Be}_{2} \mathrm{Si}_{2} \mathrm{O}_{7}\right)}$ & 3468 & 289 \\
\hline & Фенакит & $\mathrm{Be}_{2} \mathrm{SiO}_{4}$ & 2042 & 316 \\
\hline & Берилл & $\mathrm{Be}_{3} \mathrm{Al}_{2}\left(\mathrm{Si}_{6} \mathrm{O}_{18}\right)$ & 9180 & 329 \\
\hline & * Хризоберилл. & $\mathrm{Be}_{2}\left(\mathrm{AlO}_{2}\right)_{2}$ & 2299,0 & \\
\hline
\end{tabular}


На основании сравнения величин $-\Delta_{f} \bar{G}^{0}$ вышеуказанных минералов бериллия можно составить термодинамический ряд по уменьшению их реакционной способности: $\mathrm{Fe}_{8}\left(\mathrm{BeSiO}_{4}\right)_{6} \mathrm{~S}_{2}>\mathrm{Zn}_{8}\left(\mathrm{BeSiO}_{4}\right)_{6} \mathrm{~S}_{2}>\mathrm{Mn}\left(\mathrm{BeSiO}_{4}\right)_{3}>\mathrm{Be}_{4}\left(\mathrm{Si}_{2} \mathrm{O}_{7}\right)(\mathrm{OH})_{2}>\mathrm{Al}_{2}\left(\mathrm{Be}_{2} \mathrm{Si}_{2} \mathrm{O}_{8}\right)(\mathrm{OH})_{2}>$

$\mathrm{Ba}\left(\mathrm{Be}_{2} \mathrm{Si}_{2} \mathrm{O}_{7}\right)>\mathrm{Be}_{2} \mathrm{SiO}_{4}>\mathrm{Be}_{3} \mathrm{Al}_{2}\left(\mathrm{Si}_{6} \mathrm{O}_{18}\right)>\mathrm{Be}\left(\mathrm{AlO}_{2}\right)_{2}$.

Оказалось, что величина средней атомной энергии Гиббса образования $-\Delta_{f} \bar{G}^{0}$ (кДж/моль·атом) закономерно меняется при переходе от даналита к хризобериллу: их ход симбатен изменению величин, найденных в результате проведение эксперимента (таблица 1).

Величина средней атомной энергии Гиббса образования $\left(\Delta_{f} \bar{G}^{0}\right)$ может служить мерой оценки реакционной способности минерала по отношению к действию реагентов: по ней можно количественно предсказать последовательность перехода минералов в раствор при обработке его соответствующими реагентами.

Так, например, из сопоставления термодинамических свойств минералов бериллия следует, что даналит должен обладать наибольшей реакционной способностью к действию комплексообразующих реагентов и окислителей, так как у него значение $\Delta_{f} \bar{G} 0$ меньше, чем у гентгельвина, гельвина (таблица 1).

Следовательно, для полного перевода бериллия из даналита в раствор при прочих равных условиях должно затрачиваться меньше энергии, т.е. взаимодействие даналита при прочих равных условиях с растворяющими реагентами должно идти легче, чем у остальных минералов бериллия. Близки к нему по химической активности гентгельвин, гельвин, бертрандит. Далее по химической активности следуют эвклаз, бавенит, барилит, фенакит, берилл, хризоберилл. Среди минералов бериллия наибольшим отрицательным значением $\Delta_{f}$ $\bar{G}^{0}$ обладают фенакит и берилл, и именно они оказались наиболее устойчивыми по отношению к действию реагентов. Высокие отрицательные значения $\Delta_{f} \bar{G} 0$ фенакита и берилла по сравнению с остальными вышележащими минералами (таблица 1) также указывают на то, что эти вещества, в частности фенакит и берилл, должны оставаться инертными в условиях, в которых происходит полное или заметное растворение минералов даналита, гентгельвина, гельвина, бентрандита, эвклаза, барилита. Справедливость таких прогнозов можно показать на экспериментальных данных по извлечению ионов металлов из твердой фазы в раствор, полученные (при прочих равных условиях), для минералов бериллия (таблица 2).

Таблица 2 - Сравнительные данные по извлечению бериллия из минералов бериллия с различными термодинамическими характеристиками в раствор при обработке некоторыми комплексообразующими реагентами (размер частиц-0,074мм, навеска-200мг, объем растворителя 500мл)

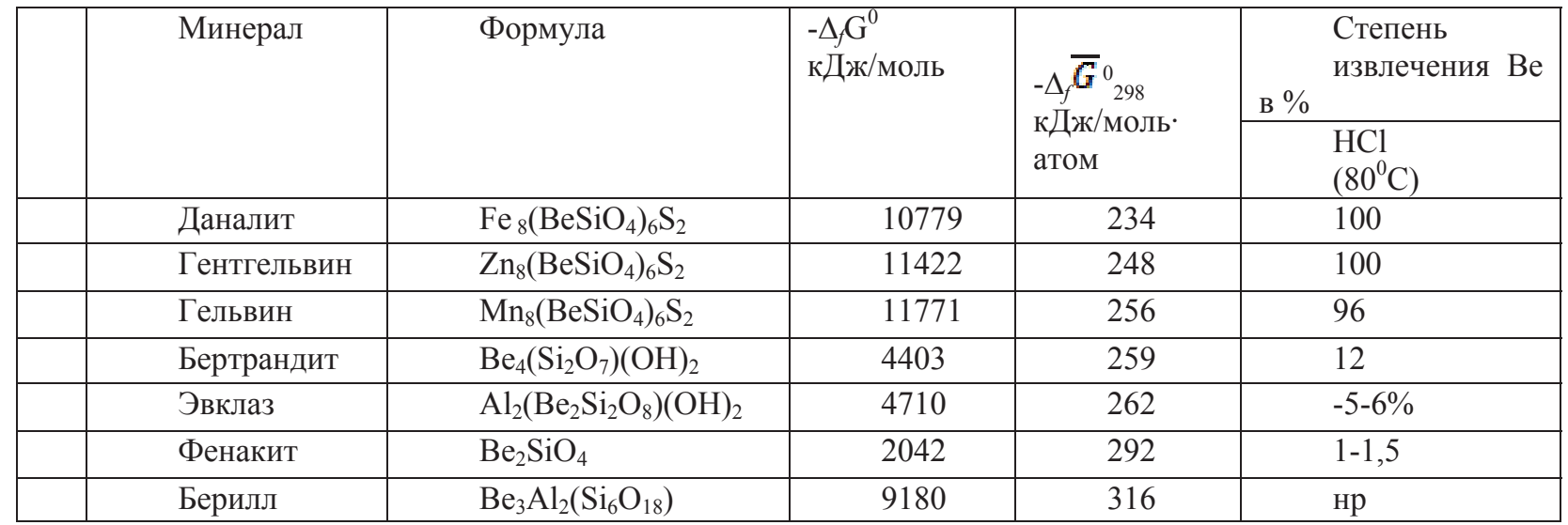

Следовательно, для полного перевода бериллия из группы минералов гентгельвина в раствор при прочих равных условиях под действием растворителя должно затрачиваться 
меньше энергии, т.е. взаимодействие группы гентгельвинов, (даналит, гентгельвин, гельвин) с соляной кислотой, например, должно идти легче, чем бертрандита, фенакита и, в особенности, берилла, т.к. последний имеет наибольшее отрицательное значение $-\Delta_{f} \bar{G}{ }_{298}$ (таблица 1).

Поведение каждого минерала изучалось как в отдельности, так и в смесях в соответствующих растворителях в зависимости от различных факторов (концентрации используемого растворителя, продолжительности перемешивания - времени контакта твердой фазы с жидкостью, скорости перемешивания, размера частиц).

В случае определения кинетических параметров порошкообразные минералы $(0,104 \pm 0,074 \mathrm{Mм})$ определенной массы помещали в реакционную ячейку емкостью 150 мл и приливали растворитель определенной концентрации, герметично закрывали крышкой и встряхивали реакционный сосуд в течении определенного промежутка времени с частотой 140-150 колеб/мин. Затем раствор отфильтровывали, а остаток 5-6 раз промывали раствором, соответствующего состава. В фильтрате определяли количество металла, перешедшего из твердой фазы в раствор.

При этом кинетические параметры рассчитывают только на восходящем начальном участке кинетической кривой, когда поверхность минерала еще остается свободной от продуктов реакции, или масса продуктов реакции весьма незначительна на поверхности исходного минерала, а концентрация активных участков на ней фактически сохраняется одинаковой [12] *. Содержание металла определяли атомно-абсорбционным методом.

Таблица 3 - Стандартные энергии Гиббса растворения минералов бериллия в соляной кислоте и их приведенные значения химического сродства $\Delta_{r} G^{0} / \mathrm{n}$.

\begin{tabular}{|c|c|c|c|c|}
\hline \multirow[t]{2}{*}{ № } & \multirow[t]{2}{*}{ Реакции } & \multirow{2}{*}{$\begin{array}{l}-\Delta_{r} G^{0}{ }_{298} \\
\text { кДж/моль } \\
\text { реакции }\end{array}$} & $\begin{array}{l}-\Delta_{r} G_{298}^{0} / \mathrm{n} \\
\text { кДж/моль }\end{array}$ & $\begin{array}{l}-\Delta_{r} G^{0} 373 / \mathrm{n} \\
\mathrm{\kappa Дж/моль}\end{array}$ \\
\hline & & & $\begin{array}{c}\text { В } \\
\text { пересчете } \\
\text { на } 1 \\
\text { моль } \mathrm{HCl}\end{array}$ & $\begin{array}{c}\text { В } \\
\text { пересчете } \\
\text { на } 1 \\
\text { моль } \mathrm{HCl} \\
\end{array}$ \\
\hline 1 & $\begin{array}{l}\mathrm{Fe}_{8}\left(\mathrm{BeSiO}_{4}\right)_{6} \mathrm{~S}_{2(\mathrm{~K})}+3 \mathrm{O}_{2(\mathrm{p})+}+36 \mathrm{HCl} \rightarrow 6 \mathrm{BeCl}_{2^{-}} \\
8 \mathrm{FeCl}_{3(\mathrm{p})}+2 \mathrm{~S}^{0}+6 \mathrm{SiO}_{2}+18 \mathrm{H}_{2} \mathrm{O} \text { (1) }\end{array}$ & $\begin{array}{l}1394 \\
\mathrm{n}=36\end{array}$ & 38,7 & 83,6 \\
\hline 2 & $\begin{array}{l}\mathrm{Zn}_{8}\left(\mathrm{BeSiO}_{4}\right)_{6} \mathrm{~S}_{2(\mathrm{~K})}+28 \mathrm{HCl}_{(\mathrm{p})}+2 \mathrm{O}_{2(\mathrm{p})} \rightarrow \\
8 \mathrm{ZnCl}_{2(\mathrm{p})}+6 \mathrm{BeCl}_{2(\mathrm{p})}+6 \mathrm{~S}^{0}+3 \mathrm{SiO}_{2}+14 \mathrm{H}_{2} \mathrm{O}(2)\end{array}$ & $\begin{array}{l}825 \\
\mathrm{n}=28\end{array}$ & 30 & 75,2 \\
\hline 3 & $\begin{array}{l}\mathrm{Mn}_{8}\left(\mathrm{BeSiO}_{4}\right)_{6} \mathrm{~S}_{2(\mathrm{~K})}+28 \mathrm{HCl}_{(\mathrm{p})}+2 \mathrm{O}_{2(\mathrm{p})} \rightarrow \\
8 \mathrm{MnCl}_{2(\mathrm{p})}+6 \mathrm{BeCl}_{2(\mathrm{p})}+6 \mathrm{~S}^{0}+3 \mathrm{SiO}_{2}+14 \mathrm{H}_{2} \mathrm{O}(3)\end{array}$ & $\begin{array}{l}800 \\
\mathrm{n}=28\end{array}$ & 29 & 35 \\
\hline 4 & $\mathrm{Be}\left(\mathrm{AlO}_{2}\right)_{2}+8 \mathrm{HCl}_{(\mathrm{p})} \rightarrow \mathrm{BeCl}_{2(\mathrm{p})}+2 \mathrm{AlCl}_{3(\mathrm{p})}+4 \mathrm{H}_{2} \mathrm{O}_{(\mathrm{p})}(4)$ & $\begin{array}{l}155 \\
\mathrm{n}=8\end{array}$ & 19,3 & 21 \\
\hline 5 & $\mathrm{Be}_{2} \mathrm{SiO}_{4(\mathrm{~K})}+4 \mathrm{HCl}_{(\mathrm{p})} \rightarrow 2 \mathrm{BeCl}_{2(\mathrm{p})}+\mathrm{SiO}_{2}+2 \mathrm{H}_{2} \mathrm{O}_{(\mathrm{p})}(5)$ & $\begin{array}{l}58,6 \\
\mathrm{n}=4\end{array}$ & 14,4 & 16 \\
\hline 6 & $\begin{array}{l}\mathrm{Be}_{3} \mathrm{Al}_{2}\left(\mathrm{Si}_{6} \mathrm{O}_{18}\right)(\mathrm{K})+12 \mathrm{HCl} \rightarrow 3 \mathrm{BeCl}_{2(\mathrm{p})}+2 \mathrm{AlCl}_{3(\mathrm{p})}+6 \mathrm{SiO}_{2}+6 \mathrm{H}_{2} \mathrm{O} \\
(6)\end{array}$ & $\begin{array}{l}-502 \\
\mathrm{n}=12\end{array}$ & -42 & -20 \\
\hline
\end{tabular}

Применительно к производственным условиям, все эксперименты проводились с частицами крупностью 0,074мм (или 200 меш.), и более крупной навеской (250г) в большом объеме аппаратуры емкостью до 1 литра.

После выбора оптимальных условий для полного вскрытия минералов содержание бериллия определяли как в смесях минералов, так и в смесях пустой породы, затем непосредственно из руд и продуктов их переработки (концентрат).

При разработке инновационной технологии с использованием процессов, протекающих в неравновесных условиях, необходимо их теоретическое изучение, которое позволило бы, во-первых, осуществить прогноз выбора эффективно действующих растворяющих реагентов для вскрытия труднорастворимых минералов при 
гидрометаллургическом способе переработки минерального сырья, во-вторых, осуществить прогноз последовательного прохождения конкурирующих сложных реакций. Тем самым создать общий принцип выбора растворителей для вскрытия труднорастворимых минералов при гидрохимическим способе переработки минерального сырья. В гидрохимическом процессе участвующие в реакции минералы и растворяющие реагенты - равноправные участники. Следовательно, прогноз последовательного прохождения конкурирующих сложных реакций, протекающих на границе раздела твердое тело-жидкость, можно проанализировать с учетом не только физико-химических свойств самих минералов и растворяющих реагентов, но и характера их взаимодействия.

Количественный характер их взаимодействия, на первом этапе, определяется приведенной величиной химического сродства реакций, протекающих в условиях переработки минерального сырья. Общеизвестно, что интенсивность протекания химических реакций зависит от способности различных веществ взаимодействовать между собой. В этом громадная роль отводится термодинамическим и кинетическим характеристикам.

Поскольку процесс взаимодействия минерала с растворяющими реагентами идет с различными энергетическими затратами в зависимости не только от природы минералов и растворяющих реагентов, но и от структурных единиц минералов, которые включают в себя различные количества неодинаковых атомов, и различные типы связи, в ходе реакции изменяются структура и свойства жидкости[13-16]. При этом определяющее влияние на формирование структуры твердого вещества оказывает природа связи.

В процессе растворения твердого вещества (минерала) в данном растворяющем реагенте, происходят два процесса: первый процесс - разрушение кристаллической решетки минерала под действием растворяющего реагента и второй процесс - освободившиеся свободные ионы металлов переходят из твердой фазы минералов в раствор, связываются с анионами, образуя соли, либо связываются с лигандами.

Эти два процесса характеризуются энергиями взаимодействия минералов с растворяющим реагентом, в частности, суммарная энергия взаимодействия минерала с растворяющим реагентом состоит из двух энергий: первая - энергия разрушения кристаллической решетки минералов под действием растворяющего реагента $\Delta_{\mathrm{r}} \mathrm{G}_{\mathrm{I}}^{0}$, и вторая - энергия связывания $\Delta_{\mathrm{r}} \mathrm{G}_{\text {II }}^{0}$ ионов, перешедших из твердой фазы в раствор анионами в виде соли или лигандами в виде комплексных соединений [11].

Используя приведенное значение нового химического сродства, можно также осуществлять прогноз последовательности прохождения конкурирующих реакций растворения (окисления) различных твердых веществ (минералов) по отношению к данному реагенту (окислителю, лиганду), т.е., иначе говоря, по величине $\Delta_{\mathrm{r}} \mathrm{G}^{0} / \mathrm{n}$ можно судить о различии реакционной способности минералов без проведения эксперимента. Сущность метода заключается в том, что в этом случае исследуются взаимодействия различных минералов по отношению только к одному растворяющему реагенту. Затем рассчитываются величины приведенного значения химического сродства $\Delta_{\mathrm{r}} \mathrm{G}^{0} \mathrm{n}$.

Как показано в таблице 3, приведенная величина изменения химического сродства взаимодействия минералов с растворяющими реагентами $\Delta_{\mathrm{r}} \mathrm{G}^{0} / \mathrm{n}$ очень важный фактор, позволяющий осуществить прогноз не только в различии реакционной способности минералов по отношению к данному реагенту, но и прогнозировать последовательность прохождения конкурирующих реакций, протекающих на границе раздела твердое теложидкость. Результаты по изменению величины $\Delta_{\mathrm{r}} \mathrm{G}^{0} / \mathrm{n}$ приводимые в таблице 3 во всех случаях для силикатов бериллия, однозначно указывают, что ход последовательного изменения значения приведенного значения химического сродства $\Delta_{\mathrm{r}} \mathrm{G}^{0} / \mathrm{n}$ и ход последовательного изменения средней атомной энергии Гиббса образования $-\Delta_{f} G^{0}$ фактически совпадают (хотя их знаки противоположны) (таблица 1).

* Минералы бериллия и руды содержащие бериллий (гельвин, гентгельвин) представлены сотрудниками Уральского научного центра г. Сверловск, за что авторы выражают им свою признательность. 
Последовательность протекания процессов взаимодействия минералов бериллия, при прочих равных условиях, совпадает с термодинамическим рядом, составленным на основании сравнения среднеатомной энергии Гиббса $\left(\Delta_{f} \overline{G^{0}}\right)$ ( таблица 2-3).

Из термодинамического анализа процессов взаимодействия минералов бериллия в растворах соляной кислоты (таблицы 2-3), следует, что с энергетической точки зрения вероятность последовательного растворения минералов уменьшается в ряду:

$\mathrm{Fe}_{8}\left(\mathrm{BeSiO}_{4}\right)_{6} \mathrm{~S}_{2}>\mathrm{Zn}_{8}\left(\mathrm{BeSiO}_{4}\right)_{6} \mathrm{~S}_{2}>\mathrm{Mn}\left(\mathrm{BeSiO}_{4}\right)_{3}>\mathrm{Be}_{4}\left(\mathrm{Si}_{2} \mathrm{O}_{7}\right)(\mathrm{OH})_{2}>\mathrm{Al}_{2}\left(\mathrm{Be}_{2} \mathrm{Si}_{2} \mathrm{O}_{8}\right)(\mathrm{OH})_{2}>$ $\mathrm{Ba}\left(\mathrm{Be}_{2} \mathrm{Si}_{2} \mathrm{O}_{7}\right)>\mathrm{Be}_{2} \mathrm{SiO}_{4}>\mathrm{Be}_{3} \mathrm{Al}_{2}\left(\mathrm{Si}_{6} \mathrm{O}_{18}\right)>\mathrm{Be}\left(\mathrm{AlO}_{2}\right)_{2}$.

Так, наибольшее абсолютное (отрицательное) значение $\Delta_{\mathrm{r}} \mathrm{G}^{0} / \mathrm{n}$ характерное для реакций (1) и (2), (3) (таблица 2) свидетельствует о том, что растворение группы минералов гентгельвина под действием вышеуказанных растворителей при прочих равных условиях должно протекать намного легче, чем у других минералов бериллия.

Такое поведение группы минералов гентгельвина в условиях растворения совпадает с его положением в термодинамическом ряду, составленном на основании средней атомной энергии Гиббса образования $-\Delta_{\mathbf{f}} \bar{G}^{0}$ (таблица 1 ).

Из анализа данных таблицы 2 также следует, что растворение фенакита и берилла в растворе соляной кислоты энергетически затруднено $\left(\Delta \mathrm{rG}^{0} / \mathrm{n}\right.$ кДж/моль) из-за менее отрицательного значения изменения величины приведенного химического сродства для фенакита и, соответственно, положительного значения $\Delta \mathrm{rG}^{0} / \mathrm{n}$ для берилла.

Следовательно, минерал берилл среди всех минералов бериллия менее реакционноспособен, и можно предположить, что он будет оставаться инертным к действию соляной кислоты (таблица 2-3) Из этого вытекает, что для полного вскрытия бериллия из фенакита и берилла надо искать другой растворитель среди кислород- и хлорсодержащих соединений, более активный, нежели соляная кислота.

Из вышесказанного можно определить место и роль энергии разрушения кристаллической решетки твердого вещества (минерала) для оценки эффективности действующих реагентов для вскрытия труднорастворимых минералов.

Поскольку определенный практический интерес как перспективное сырье представляют минералы бериллия [1]: даналит, гентгельвин, гельвин, они составляют основу гентгельвинового концентрата. Поэтому нами проводились экспериментальные исследования по растворению в соляной кислоте с вышеуказанными минералами бериллия.

Проверка этих данных на мономинеральных образцах даналита, гельвина, гентгельвина в пределах концентрации соляной кислоты от 0,8 до 12\% (по объёму) показала, что лучшие результаты по извлечению бериллия из группы гентгельвина достигаются при концентрации $8 \% \mathrm{HCl}$ (по массе).

Наши предварительные экспериментальные результаты по изучению поведения гельвина (гентгельвина) в зависимости от концентрации соляной кислоты позволили получить информацию об основных факторах, влияющих на изучаемый процесс: концентрация соляной кислоты, продолжительность перемешивания, температура.

С целью нахождения наиболее эффективных вариантов оптимальных условий избирательного растворения гельвина (гентгельвина) в присутствии других минералов бериллия, в частности хризоберилла, фенакита, использовано ортогональное планирование эксперимента 2-го порядка с «звездным плечом» $\alpha= \pm 1,215$.

Уровни факторов и интервалы варьирования матрицы планирования и результаты эксперимента приведены в таблице 4.

Опыты проводились только с гельвином, поскольку хризоберилл и фенакит фактически обладают малой реакционной способностью, нежели гельвин (таблица 1). Зависимой переменной являлась степень извлечения бериллия из гельвина.

После обработки данных находили значения коэффициентов регрессии. Оценку значимости этих коэффициентов проводили с учетом дисперсии. Ошибку эксперимента рассчитывали из четырех определений в центре плана. 
Таблица 4 - Уровни факторов и интервалы варьирования матрицы планирования и результаты эксперимента

\begin{tabular}{|l|l|l|l|}
\hline \multirow{2}{*}{ Характеристика } & $\mathrm{X}_{1}, \%$ & $\mathrm{X}_{2}, \mathrm{мин}$ & $\mathrm{X}_{3}$, град \\
\cline { 2 - 4 } & {$[\mathrm{HCl}]$} & $\mathrm{t}$, время & $\mathrm{T}^{0} \mathrm{C}$ \\
\hline Область исследования & $2-10$ & $5-60$ & $50-100$ \\
\hline Центр плана & 6,0 & 32,5 & 75 \\
\hline Интервал варьирования & 2,8 & 19,4 & 17 \\
\hline Верхний уровень & 10,0 & 60 & 100 \\
\hline Нижний уровень & 2 & 5 & 50 \\
\hline+1 & 8,8 & 51,9 & 92 \\
\hline-1 & 3,2 & 13,1 & 62 \\
\hline
\end{tabular}

Таблица 5- Матрица планирования и результаты опытов

\begin{tabular}{|l|c|c|l|l|l|l|l|l|l|l|}
\hline $\begin{array}{l}\text { № } \\
\text { пп }\end{array}$ & $\mathrm{x}_{1}$ & $\mathrm{x}_{2}$ & $\mathrm{x}_{3}$ & $\mathrm{~B}_{1} \mathrm{~B}_{2}$ & $\mathrm{~B}_{2} \mathrm{~B}_{3}$ & $\mathrm{~B}_{1} \mathrm{~B}_{3}$ & $Z_{2}, \%[\mathrm{HCl}]$ & t, мин & $\mathrm{C}^{0}$, град. & у, Ве \% \\
\hline 1 & + & + & + & + & + & + & 8,0 & 51,9 & 92 & 88 \\
\hline 2 & - & + & - & - & - & + & 3,2 & 13,1 & 62 & 19 \\
\hline 3 & + & - & - & - & + & - & 8,0 & 13,1 & 62 & 25 \\
\hline 4 & - & - & + & + & - & - & 3,2 & 13,1 & 92 & 62 \\
\hline 5 & + & + & - & + & - & - & 8,0 & 51,9 & 62 & 45 \\
\hline 6 & - & + & + & - & + & - & 3,2 & 51,9 & 92 & 76 \\
\hline 7 & + & - & + & - & - & + & 8,0 & 13,1 & 92 & 80 \\
\hline 8 & - & - & - & + & + & + & 3,2 & 32,5 & 62 & 22 \\
\hline 9 & 0 & 0 & 0 & 0 & 0 & 0 & 6,0 & 60 & 75 & 45 \\
\hline 10 & $+1,215$ & 0 & 0 & 0 & 0 & 0 & 10 & 32,5 & 75 & 60 \\
\hline 11 & $-1,215$ & 0 & 0 & 0 & 0 & 0 & 2,0 & 32,5 & 75 & 35 \\
\hline 12 & 0 & $+1,215$ & 0 & 0 & 0 & 0 & 6,0 & 60 & 75 & 55 \\
\hline 13 & 0 & $-1,215$ & 0 & 0 & 0 & 0 & 6,0 & 5 & 75 & 40 \\
\hline 14 & 0 & 0 & $+1,215$ & 0 & 0 & 0 & 6,0 & 32,5 & 100 & 100 \\
\hline 15 & 0 & 0 & 1,215 & 0 & 0 & 0 & 6,0 & 32,5 & 50 & 30 \\
\hline 16 & 0 & 0 & 0 & 0 & 0 & 0 & 6,0 & 32,5 & 75 & 47 \\
\hline 17 & 0 & 0 & 0 & 0 & 0 & 0 & 6,0 & 32,5 & 75 & 48 \\
\hline 18 & 0 & 0 & 0 & 0 & 0 & 0 & 6,0 & 32,5 & 75 & 42 \\
\hline
\end{tabular}

*Поскольку даналит, гельвин и гентгельвин обладают почти одинаковой химической активностью по отношению в соляной кислоте (таблица 1), то опыты по планированию эксперимента проводили только с гельвином.

Вычисленное по результатам планирования (таблица 5) уравнение регрессии: $\mathrm{y}=50,2+8,2 \mathrm{x}_{1}+5,2 \mathrm{x}_{2}+25,6 \mathrm{x}_{3}+2,1+2,1 \mathrm{x}_{1} \mathrm{x}_{2}-3,1 \mathrm{x}_{1}+8,8 \mathrm{x}_{3}$

адекватно описывает изучаемый процесс.

Fрасч. $=6,4$

Fрасч. $<$ Fтабл. $\quad$ Fтабл. $(0,95: 5,3)=9,01$

На основе применения планирования эксперимента выбраны следующие наиболее эффективные оптимальные условия извлечения бериллия из даналита, гельвина и гентгельвина в присутствии хризоберилла: 100 мл 5-8\%-ного раствора соляной кислоты при кипячении в течение 30 минут. В этих условиях определялись степени извлечение бериллия из гельвина и гентгельвина и она составляет $100 \%$, из хризоберилла-5,0\%-6,0\%, а из фенакита-1-1,5\%.

Следует отметить, что тем более сравнительный анализ величин приведенного значения химического сродства $\Delta_{r} G \frac{0}{\mathrm{n}}$ растворения силикатов бериллия в соляной кислоте в таблицах 2, 5 показывают, что с энергетической точки зрения последовательность их растворения 
происходит в ряду от даналита к бериллу. При этом наибольшая вероятность, того что весьма легко будут растворятся даналит, гентгельвин, гельвин.

Экспериментальная проверка данного теоретического прогноза последовательности растворения минералов бериллия на основе $\Delta_{f} \bar{G}^{0}$ и $\Delta_{r} G \%$ п показала, что при обработке $8 \%$ раствором соляной кислоты минералов бериллия при кипячения в течение 60 минут извлечение бериллия из даналита, гентгельвина и гельвина составляет 100 \% , а из хризобериллия 5-6\%, из фенакита 1-1,5\%. Берилл в этих условиях практически не растворяется. Следовательно, ход изменения степень извлечения бериллия из твердой фазы минералов бериллия в раствор и ход изменения $\Delta_{f} \bar{G}^{0}$ и $\Delta_{r} G \%$ с совпадают.

\section{Выводы}

1. Осуществлен качественный и количественный прогноз различия реакционной способности для минералов бериллия, где их реакционная способность симбатно изменяется с изменением величины $\Delta_{f} \bar{G}^{0}$ по отношению к данному реагенту без проведения эксперимента, впоследствии подтвержденным многочисленными экспериментальными кинетическими характеристиками (W, K).

2. Осуществлен количественный прогноз эффективности растворяющих реагентов для вскрытия бериллия из группы гентгельвинов (бериллийсодержащего сырья) на основе сопоставления рассчитанной энергии разрушения кристаллической решетки минералов бериллия (новое приведенное значение химического сродства $\left(\Delta_{\mathrm{r}} \mathrm{G}^{0} / \mathrm{n}\right)$ под действием растворяющих реагентов, а также спрогнозирована последовательность прохождения конкурирующих реакций растворения минералов бериллия в различных растворяющих реагентах.

3. Теоретически и экспериментально доказано, также на примерах минералов бериллия, что приведенное значение $\left(\Delta_{\mathrm{r}} \mathrm{G}^{0} / \mathrm{n}\right)$, в общем случае, служит критерием для решения важной проблемы при переработке минерального сырья гидрохимическим методом: во-первых, прогноз различия реакционной способности твердых веществ (минералов) по отношению к данному реагенту. Во-вторых, для качественного и количественного прогноза эффективности действия растворяющих реагентов для полного вскрытия (разложения) труднорастворимых минералов. В-третьих, позволяет осуществить прогноз последовательного прохождения конкурирующих реакций, протекающих на границе раздела твердое тело-жидкость. В этом заключается новизна данного открытия. Все эти прогнозы опираются на теоретический учет влияния основных факторов, определяющих направления и скорости протекающих реакций. Разработка общего принципа прогноза особенно важна и актуальна при совершенствовании и разработке новых технологий, не проводя трудоемких экспериментов с наименьшими затратами времени.

4. Методом математического планирования эксперимента исследовано влияние различных факторов (концентрация соляной кислоты, и система хлор-вода, продолжительности кипячения раствора). Получены уравнения регрессии, позволяющие определить максимальную степень извлечения бериллия из группы минералов гентгельвина (степень извлечения бериллия из их мономинеральных образцов составляет 100\%).

5. Предложены способы полного вскрытия бериллия из группы минералов гентгельвина соляной кислотой при нагревании $80 \mathrm{C}^{\circ}$ в течение одного часа.

Предложенный способ вскрытия группы минералов гентгельвина с использованием солянокислого раствора может быть основой инновационной технологии переработки бериллия из гентгельвинового концентрата. 


\section{Литература}

1. Эверест Д. Химия беррилия. - М.:Химия, 1968.

2. Плющев В.Е., Степанина С.Б., Федоров П.И. Химия и технология редких и рассеянных элементов часть 1.// под.ред.Большакова-М., - 1976.-186-221.

3. Силина Г.Ф., Зарембо Ю.И., Бертина Л.Э. Химическая технология и металлургия// Атомиздат - 1960.-С.2035.

4. Cleaver G.H //Engng and Min J 1554.- №7.-P.98.

5. Нисигаки С., Маэкава К./Патент № 17123-1962.

6. Дарвин Дж., Барддари Дж. Бериллий// Л.-1962.-С.50-75.

7. Аналитическая химия бериллия. - М.:Наука,1966.-С.79.

8. Коленикова М.А,Крейн О.Е. Металлургия рассеяных и легких редких металлов.М., Металлургия, 1977. - C 300-357.

9. Сонтина О.А. Редкие металлы. М: Металлургия,1964. - С.429-453.

10. В.В. Потоцкий Научные открытия, идеи, гипотезы. (1992-2007г информационно- аналитическое издательство. - М., 2008 г. - С.230-231.

11. Оспанов Х.К. Общие принципы прогнозирования различных реакционных способностей минералов и растворителей в условиях переработки минерального сырья (по материалом трех международных научных изданий) учебное пособие. - А., Изд.ТОО «ВTS paper». - 2012 г. - С 305.

12. Научные открытия ( сборник кратких отношений научных открытии, научных гипотез)- Москва, 2004.Диплом № 238 Автор: д.Х.н. Оспанов Х.К., КазНУим.аль-Фараби.с 34-37.

13. Оспанов Х.К. Физико-химические основы избирательного растворения минералов. - М: Недра,1993. C. 173

14. Оспанов Х.К. Термодинамика и кинетика гетерогенных процессов (неравновесных) протекающих на границе раздела фаз твердое тело-жидкость. А.:Комплекс, 2006. - С.360

15. Оспанов Х.К. Теория управления физико-химических процессов на границе раздела фаз и перспективе ее использования. - А.:Комплекс, 2004 год. с.126

16. Ospanov Kh. K., Ospanov A. Kh. Physico-chemical bases for treatment of gold-containig raw materials by the method of wet chlorination - L.: Flintriver, 2004.- P-130.

17. Веденеев В.И., Гурвич Л.В. и др. Энергии разрыва химических связей. Потенциал ионизации и сродства к электрону.// Спр.М.: Изд-во «АНСССР» 1962. - С.55,90,143.

18. Ospanov Kh.K. Physical and Chemical foundations for selective dissolution of minerals. - L.: Flintriver, 2004. $175 \mathrm{p}$.

19. Ospanov Kh.K. Theory of controlling. A physico-chemical process- taking place at the interface solid-liquid. L.: Flintriver, 2004. - 130 p.

20. Оспанов Х.К., Оспанов А.Х. Физико-химические основы переработки золотосодержащего сырья методом мокрого хлорирования. - Алматы, 2000. - 201 с.

\section{МИНЕРАЛДЫҚ ШИКІЗАТТЫ ҚАЙТА ӨНДЕУ ЖАҒДАЙЫНДАҒЫ ГЕНТГЕЛЬВИН ТОБЫНЫҢ МИНЕРАЛДАРЫНАН БЕРИЛЛИЙ АЛУДЫҢ ТӘСІЛІН ӨНДЕУ}

Х.Қ. Оспанов, F.М. Мүтанов, Б.Ж. Арынов, С.Қ. Қожақметов, В.А. Рыбакова, Н.Х. Оспанова, А.Б. Байболдиева

Термодинамикалық, кинетикалық зерттеулердің және экспериментік математикалық жобалау әдісініңнегізінде бериллийді гентгельвиндер тобының минералдарынан алу жолдары ұсынылды.

\section{DEVELOPMENT OF A WAY OF EXTRACTION OF BERYLLIUM FROM GENTHELVITE GROUP OF MINERALS UNDER THE CONDITIONS OF PROCESSING OF MINERAL RAW MATERIALS}

Kh.K. Ospanov, G.M. Mutanov, B.J. Arynov, S.K. Kojakhmetov, V.A. Rybakova, N.Kh. Ospanova, A.B. Baiboldieva

On the basis of thermodynamic, kinetic researches and by method of mathematical planning of experiment the way of extraction of beryllium from group of genthelvite minerals is offered. 